Check for updates

London

Cite this as: $B M J$ 2021;372:n823 http://dx.doi.org/10.1136/bmj.n823 Published: 25 March 2021

\section{Covid-19: Lateral flow tests are better at identifying people with symptoms, finds Cochrane review}

\author{
Shaun Griffin
}

Rapid antigen (lateral flow) tests are better at identifying covid-19 infection in people with symptoms than in those with none, although the diagnostic accuracy of different brands of tests varies widely, a Cochrane review has found.

The review's lead author criticised the UK government for rolling out the lateral flow testing programme in the absence of empirical evidence.

The latest report updates previous reviews ${ }^{2}$ and includes evidence from 64 studies up to November 2020. Most were conducted in Europe and the United States and assessed the accuracy of lateral flow tests in detecting current SARS-CoV-2 infection when compared with the standard laboratory genome testing.

The World Health Organization's performance standards require that tests correctly identify at least $80 \%$ of infected people (test sensitivity) and exclude infection in at least $97 \%$ of uninfected people (test specificity). The Cochrane analysis found that test sensitivity in symptomatic people ranged from $34 \%$ to $88 \%$, with an average of $72 \%$. The figure for the Innova test used in the UK was $58 \%$. The tests worked best in the first week after symptom onset.

In people without symptoms the tests correctly identified an average of $58 \%$ of those who were infected. However, the number of samples from asymptomatic people was around 10 times lower than from symptomatic people in the studies analysed, limiting the conclusions that could be drawn, said the authors.

In uninfected people the tests correctly ruled out infection in $99.5 \%$ of people with covid-19-like symptoms and in $98.9 \%$ of those without.

The performance of the Innova lateral flow test in asymptomatic people was not included in the analysis, as studies have yet to be published. At a Science Media Centre briefing the authors referred to two such studies, neither of which has been peer reviewed: the Liverpool lateral flow pilot, which showed a test sensitivity of $40 \%$ based on 70 cases, and a University of Birmingham study with a sensitivity of $3 \%$ based on eight cases.

Jon Deeks, professor of biostatistics at the University of Birmingham and the review's lead author, said, "These tests work a lot less well in people who are asymptomatic than symptomatic. The government has not been clear on this. The only data we have is based on the [Liverpool and Birmingham] studies, where a total of 78 people had covid-19, when 40 million tests have been given out.

"I personally find it quite shocking that the government thinks this is an adequate evidence base on which to base such a large, expensive, and quite invasive policy."

\section{Mass testing value is questioned}

The authors set out a scenario of lateral flow testing in areas with a covid-19 prevalence of $0.5 \%$, as reported in the latest UK React study. ${ }^{3}$ They concluded that the best available test would not only miss cases but would also create more false positive cases than identify real ones.

"There are gaps in the evidence behind a lot of the policies for the use of lateral flow tests, particularly in children," said Deeks, who expressed concern that policy making was being based on modelling analysis alone. The lack of data on the accuracy of repeat testing was also a concern, he said. As prevalence drops, he predicted more false positives and fewer true positive results, "so there will come the point where the harm is going to outweigh the benefits of doing [lateral flow] testing."

Jac Dinnes, review coauthor and senior researcher in public health, epidemiology, and biostatistics at the University of Birmingham, said, "Our review shows that some antigen tests may be useful in healthcare settings where covid-19 review is suspected in people with symptoms. Confirming a positive result from a rapid test with an RT-PCR [reverse transcription polymerase chain reaction] test, particularly where cases of covid-19 are low, may help avoid unnecessary quarantine.

"All antigen tests will miss some people with infection, so it is important to inform people who receive a negative test result that they may still be infected."

1 Dinnes J, Deeks J], Berhane S, etalCochrane COVID-19 Diagnostic Test Accuracy Group. Rapid, point-of-care antigen and molecular-based tests for diagnosis of SARS-CoV-2 infection. Cochrane Database Syst Rev 2021:3:CD013705.

doi: 10.1002/14651858.CD013705.pub2. pmid: 33760236

2 Wise J. Covid-19: Timing is critical for antibody tests, finds Cochrane review. BMJ 2020;369:m2584. doi: 10.1136/bmj.m2584 pmid: 32586794

3 Riley S, Wang H, Eales O, et al. REACT-1 round 9 final report: continued but slowing decline of prevalence of SARS-CoV-2 during national lockdown in England in February 2021. medRxiv 2021 [preprint]. doi: 10.1101/2021.03.03.21252856.

This article is made freely available for use in accordance with BMJ's website terms and conditions for the duration of the covid-19 pandemic or until otherwise determined by BMJ. You may use, download and print the article for any lawful, non-commercial purpose (including text and data mining) provided that all copyright notices and trade marks are retained. 